\section{Can of wormholes}

Take a trip.

I wish to make a complaint.

Select Department: Sales/Billing, Technical

Support, Pre-purchase

Technical Support.

Product: Eternitizer 3000, Alternatron D11,

MixWhizz 98

Alternatron D11.

Priority: Low, Medium, High, Critical

Critical.

Problem Area: Response time, Scan precision,

Matter transfer integrity, None of the above

None of the above.

Briefly describe the problem.

Like the manual says, I scan for an alternate and when one comes up green I press

Transfer, Enter but nothing happens. Submit.

Your enquiry is being assigned. Please wait.

My name is Troy. How may I help you today?

Is your name really Troy?

No.

Do you look anything like that photograph?

No.

Ok. Just wanted to establish an open and

honest relationship. Cute photo, though.

Understood.

Did you read my description?

Yes.

So. Any ideas?

Are the batteries charged up?

Yes, they're charged up. It comes up green.

Sorry. You wouldn't believe some people.

I get a green, I press Transfer, Enter, zilch.

Do you have it there?

Yes.

Can you press Transfer, then hold down Enter for three seconds, then release Transfer and press it quickly two more times?

$\mathrm{Ok}$, hang on. Wow, there's all this scrolling

text and flashing lights.

That's right, now scroll right down to the

bottom. What do you see?

'The portal has rejected your application for access'.

OK, good.

What does that mean? How can it reject my application?

It's just the message that gets logged, what's

really happening is they've shut down the portal.

'They'? What 'they'?

The guys in the other universe.

How can they do that?

It happens in the preferred alternate universes.

There's going to be ones that are really crap and ones that are really cool, you know, like they

have world peace and cake grows on trees and they still have unicorns and the dolphins can really talk. They end up with all these people arriving with attitudes from bad universes and bringing them all down. So they figure out how to close the portal.

I mean how can they do it? You can't close a

wormhole can you?

No, I don't know, they do something with gravitons, kind of put a knot in the string, we're working on it.

Why don't you just go to their universe and find out what they did?

We would, but they've closed the portal.

Oh yeah. But it came up green.

We know, the next version fixes it.

When's that out?

We haven't announced the release date yet, that thing has so many bugs. Last week we had this major anomaly. Our branes weren't lined up totally parallel? Bulk issues. Those worms did not want to go back in the can.

Well, I don't want to upgrade, anyway.

$O K$, there's a workaround.

I'm listening.

What you do, you get your green, then you

save the code in your favourites.

$\mathrm{OK}$.

Then you go to your favourites and select the one you just saved.

Got it.

Then you choose 'Show Me More Like This'.

Right.

Then you select the second one from the

bottom every time.

Second one from the bottom.

And you keep doing that until you find one that's open.

How do you know there's going to be one? There's an infinite number. Every zeptostate has its opposite. There has to be at least one of everything.

Has to?

It's uncountably infinite, high cardinality, like seriously a lot.

It's going to take a while to work through

them then.

It doesn't take too long, there's some quantum statistical effect, I forget its name. Helmholtz? Isn't that when someone's choking?

Heidegger?

Whatever.

Oh, and when you find one that's open, right,

you press Transfer, Enter, and it goes yellow

and says Confirm?

Yeah?

Press Enter again right away. I mean don't even hesitate for a second.

Why?

Just take my word for it.

Come on, Troy. Why?

Well, there's a chance that they'll shut the portal between the time you press the Transfer Enter, and the Confirm Enter. So you leave, but you don't arrive.

How likely is that?

Not very. Maybe in some universes it happens every time. Skip that universe, right? And where are you, if you don't arrive? It's hard to tell, we're trying to find someone who came back so we can put it in the manual. What do you think happens?

We were talking about it next to the coffee maker and this one girl, Ray, says maybe you disperse into an evenly distributed interstitial pseudoneural net with simultaneous * parapsychic access to all universes.

What made her say that?

She's always saying stuff like that.

So you would, like, be aware of every possibility of every moment. Iguess.

Could you trope? Like, metonymise? Yeah.

Search me.

That would be awesome.

It would be kind of cool.

So you just wait a while before you press Confirm Enter?

Listen, you don't know

how long you're going to have to wait. And I'm not saying it does that anyway, you know, why believe Ray?

Anyway, I wasn't trying to turn myself into some Star Child or anything, I just wanted to find a store where they haven't run out of Ginseng and Lemon tea.

Oh, really? They have that in the MegaHealth downstairs.

$\mathrm{Oh}$, really? Where are you?

Just checking where you are. Hey! I'm three

blocks down in Station Street.

Ok, I'm just going to zap over. Why don't we get together for a coffee?

Sounds good.

Give me your co-ords. Wait a minute, now this universe isn't coming up green. What does that mean? ... Troy? Troy?

\section{Neale Morison}

Neale Morison is a writer of words and code, currently lurking around Harvard and MIT.

Contact him at www.nealemorison.com. 